Research Article

\title{
Numerical Approximation of Blast Loads on Confined Dry-Stacked Masonry Wall
}

\author{
Muhammad Ishfaq, ${ }^{1}$ Azmat Ullah,, ${ }^{1}$ Awais Ahmed, ${ }^{1}$ Sarfraz Ali, ${ }^{3}$ Syed Muhmmad Ali, ${ }^{1}$ \\ Marjan Uddin $(\mathbb{D})^{2}$ and Khan Shahzada $\mathbb{D}^{1}$ \\ ${ }^{1}$ Department of Civil Engineering, University of Engineering \& Technology, Peshawar, Pakistan \\ ${ }^{2}$ Department of Basic Sciences, University of Engineering \& Technology, Peshawar, Pakistan \\ ${ }^{3}$ Wits Mining Institute (WMI), University of the Witwatersrand, Johannesburg, South Africa
}

Correspondence should be addressed to Marjan Uddin; marjan@uetpeshawar.edu.pk and Khan Shahzada; khanshahzada@uetpeshawar.edu.pk

Received 14 September 2021; Revised 15 November 2021; Accepted 7 December 2021; Published 30 December 2021

Academic Editor: Viet-Thanh Pham

Copyright (๑) 2021 Muhammad Ishfaq et al. This is an open access article distributed under the Creative Commons Attribution License, which permits unrestricted use, distribution, and reproduction in any medium, provided the original work is properly cited.

\begin{abstract}
This research intends to numerically study the out-of-plane behaviour of confined dry-stacked masonry (CDSM) walls against blast loading. CDSM is a mortarless interlocking masonry system consisting of Hydraform blocks laid in stretcher bond with reinforced concrete (RC) confining elements. A nonlinear numerical model is developed using advanced finite element hydrocode ANSYS-Autodyn to study the response of CDSM walls subjected to explosive loads. Four different test cases using a charge weight of $4 \mathrm{~kg}, 8 \mathrm{~kg}, 12 \mathrm{~kg}$, and $16 \mathrm{~kg}$ of Wabox explosive are investigated numerically. The results obtained from numerical simulation are validated with the experimental tests results. The numerical results are found in good agreement with the experimental results. The ability of the numerical model is studied to correctly predict the pressure-time history in pressure gauges installed on walls and compared with experimental data. Peak incident overpressures obtained in these numerical tests ranged from 240 to $1000 \mathrm{kPa}$. Likewise, the damage patterns obtained from the numerical simulations are compared with available experimental results which show a satisfactory agreement. This study helps to check the response of CDSM structures against blast load which can be used for the construction of blast resisting design of buildings.
\end{abstract}

\section{Introduction}

Terrorism, after 9/11 in Pakistan, has become a devastating and extremely harmful phenomenon. The human losses are more than 70,000 and with economic cost of more than $\$ 68$ billion [1]. Terrorists mostly hit government lifeline structures such as educational institutes, healthcare facilities, police and army installations, and government infrastructures by bomb blasts which are mainly built from masonry [2]. In these scenarios, the performance of masonry walls is very critical for the structural integrity of buildings. It is very challenging to study experimentally the effects of blast load on structures due to numerous input parameters, limited financial resources, time constraints, and safety considerations. Therefore, the best alternative for such type of costly experiments is an efficient computer software and codes such as ANSYS-Autodyn [3].
Besides conventional masonry, a new masonry system of mortarless interlocking blocks, which is also known as drystack masonry, has recently been introduced in Pakistan. The typical shape of dry-stack masonry blocks (Hydraform blocks) and their masonry assemblage is shown in Figure 1. If this masonry system is confined by reinforced concrete (RC) beam and columns, then it is termed as confined drystack masonry (CDSM) system. The CDSM system was found to be more ductile and reliable in strength for lateral loads [4]. The structural strength and integrity of this masonry system depend on interlocking system of blocks between masonry units. The interlocking mechanism provides stability, self-alignment, and levelling to the walls. Hydraform blocks are manufactured from mixture of soil with at least $22 \%$ clay, $10 \%$ sand, and $6.7 \%$ cement by weight mixed using a cement mixer. Approximately, $10 \%$ water is added to 


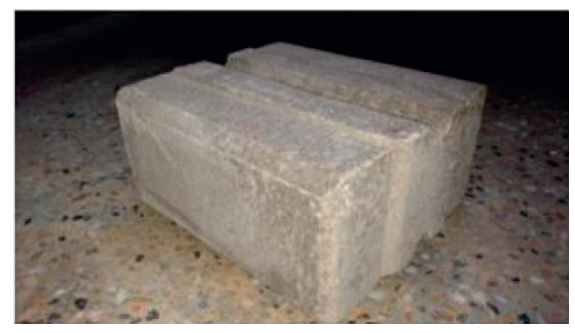

(a)

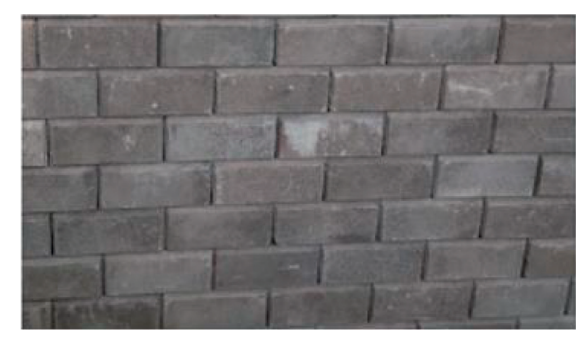

(b)

Figure 1: (a) Hydraform block. (b) Assemblage of dry-stacking Hydraform blocks.

the mixture to achieve the desired consistency for block pressing and after seven days of curing, it is used in constructing walls [5]. The construction process in this type of masonry is simplified and highly economically competitive due fast track construction and very effective where skilled labor is expensive and even unavailable. Being a sustainable building material, it is more energy efficient compared to traditional clay-bricks which require three times more energy per square metre (406 kg of $\mathrm{CO}_{2}$ emission) than Hydraform blocks (119 kg of $\mathrm{CO}_{2}$ emission) [6].

The numerical modelling of CDSM walls is complex and computationally expensive. The analysis complexity reasons are modelling of the nonlinear behaviour of an RC confining frame, modelling of the nonlinear behaviour of a dry-stacked masonry panel, and modelling the interaction between frame and masonry [7].

Several researchers in the past have studied the blast load phenomenon on various structures numerically and experimentally such as Luccioni et al. [8] who conducted a numerical study to analyse the structural failure of the reinforced concrete building under the blast load. The results were compared with actual buildings that were damaged in terrorist attacks. In another study [9], the same researcher performed numerical analysis of blast load using hydrocodes and compared the results with empirical models with a good correlation. Theobald and Nurick [10] performed numerical and experimental study to investigate the performance of tube-core claddings under blast loads. A numerical model was developed in computer program ABAQUS/Explicit for numerical simulations which shows satisfactory correlation with experimental response. Thiagarajan et al. [11] conducted numerical and experimental study to investigate the performance of doubly reinforced concrete slabs against the blast loads. They employed the commercial program LSDYNA for numerical simulations, and their numerical and experimental results were matched with a good agreement. $\mathrm{Wu}$ et al. [12] conducted a 3D and 2D numerical study by using commercial software Autodyn3D for the analysis of infilled masonry in RC frame structures subjected to ground excitations induced by blast waves. After comparison of results, they concluded that $3 \mathrm{D}$ analysis captured the real response of the structures. Ghaderi et al. [13] in 2015 used ABAQUS as numerical analyses tools to represent unreinforced brick masonry walls strengthened with $1.5 \mathrm{~mm}$ thick FRP strips fixed in various formations and subjected to a blast load based on scale-distance parameter. Finally, they observed more damage to wall as the scale-distance decreased. Scaled distance $(z)$ is parameter used for the intensity level of blast load as defined by equation (1), established by Hopkinson and Cranz [14], which relate charge weight of equivalent TNT (W) and standoff distance $(R)$.

$$
z=\frac{R}{\sqrt[3]{W}}
$$

Alsayed et al. [15] in 2016 carried out blast load tests on block masonry wall specimen confined by a frame of reinforced concrete. They conducted five tests of various charge size and standoff displacements in the field. In conclusion, they found that the numerical results, obtained from ANSYS-Autodyn, best matched for the blast load parameters such as arrival time, peak incident, and peak reflected overpressures and therefore, the numerical techniques are the valid way to analyse the walls against blast load. Edri and Yankelevsky [16] in 2018 considered a new analytical model for the dynamic response in terms of timedisplacement history of one-way arching URM walls under blast loads. Their SDOF model predictions have shown good agreement after comparisons with experimental test results. Michaloudis and Gebbeken [17] in 2019 presented in their study a modelling strategy appropriate for masonry walls subjected to far-field and contact detonations blasts to capture the local damage and debris formation. They adopted a derived material model for brick masonry from a concrete model which was already tested under blast load. Their proposed model shows good performance and combines the advantages of fully Lagrangian approaches and Smoothed Particle Hydrodynamic (SPH) approach. The delivered numerical results of the model were in good agreement with the result of experimental studies. It is concluded from abovementioned discussion that most of the recent research studies have focused on the performance evaluation of conventional masonry and RC structures while research on CDSM structures performance against blast load is limited.

The aim of this research study is to develop a 3D finite element model to systematically study the out-of-plane behaviour of CDSM wall against blast load. A full-scale CDSM wall was developed in ANSYS-Autodyn and tested against the blast loads generated from Wabox explosive. The numerical simulations were performed for different test cases. Finally, the results obtained from numerical analysis 
were compared with the data obtained from experimental tests conducted by Ullah [18] on the same masonry wall.

\section{Description of CDSM Test Wall}

The considered test model in this research is a CDSM wall shown in Figure 2, which is representative of typical masonry buildings constructed in Pakistan. The CDSM wall tested in the field by Ullah [18] and the same wall was modelled in the ANSYS-Autodyn. The CDSM wall panel is $7 \mathrm{ft}(2.134 \mathrm{~m})$ tall, $7 \mathrm{ft}(2.134 \mathrm{~m})$ wide, 8 inch $(200 \mathrm{~mm})$ thick confined by confining elements of 8 inch $\times 8$ inch $(200 \mathrm{~mm} \times 200 \mathrm{~m})$ with typical 4-\#4 (4 $\varphi 12 \mathrm{~mm})$ steel longitudinal reinforcement and \#3 $(\varphi 10 \mathrm{~mm})$ rings provided at 6 inch $(150 \mathrm{~mm})$ center-tocenter distance. All the steel rebars used in the wall specimen are tested and are of 40,000 psi (420 MPa) strength. Concrete cylinder specimens were casted during construction of test wall and tested for compressive strength after 28 days of curing. On average, compressive strength of 3000 psi $(20.70 \mathrm{MPa})$ was obtained for ordinary concrete. The Hydraform blocks available in the local market of size 8 inch $\times 8$ inch $\times 4$ inch $(200 \mathrm{~mm} \times 200 \mathrm{~mm} \times 100 \mathrm{~mm})$ have been used to construct wall specimens. The gross area compressive strength of Hydraform block is 1940 psi $(13.25 \mathrm{MPa})$ whereas based on shoulder area it is $1240 \mathrm{psi}$ $(8.50 \mathrm{MPa})$. As the stress transfer in dry-stacking condition is only through shoulders of the block, masonry prisms tested in the laboratory by applying load on the shoulders and the compressive strength of masonry were calculated as 730 psi (5.00 MPa). The Elastic Modulus from prism test was calculated as $606,660 \mathrm{psi}(4182.77 \mathrm{MPa})$. All the test results are adopted from the research study of Hafeez [19]. The cement mortar with mix proportion of $(1: 6)$ has been used in the construction of starter course of the masonry walls.

\section{Description of Testing Setup}

Wabox (TNT equivalent $=1.1$ ) explosive is used in this research study for blasting which is a nitroglycerine-based dynamite manufactured by WA Nobel PVT Ltd. Rawalpindi, Pakistan. The charge of Wabox explosive is situated $3 \mathrm{ft}$ $(915 \mathrm{~mm})$ above the ground at a distance of $12 \mathrm{ft}(3.66 \mathrm{~m})$ from the wall as shown in Figure 3. Three pressure gauges G-01, G-02, and G-03 are installed on the windward face of the wall. The pressure gauges are installed to measure the incident overpressures on the face of the wall.

Four blast tests on the same CDSM wall, namely, blast tests $\# 1$, \#2, \#3, and \#4, with varying charge weight were conducted in field by Ullah [18] carried out in Risalpure (Nowshera), Pakistan, and the same tests were modelled in ANSYS-Autodyn for calibration. In these tests, the wall was subjected to four blast load tests with increasing level of intensity and scale-distance parameter has been used for intensity level measurement; details are listed in Table 1.

\section{Material Models for Simulations}

ANSYS-Autodyn is a hydrocode which uses fundamental law of physics such as law of conservation of mass, momentum, and energy in the form of partial differential equations (PDEs). These governing PDEs including initial and boundary conditions are used to predict the response of the system materials for large deformation in nonlinear dynamic problem. The mathematical relationships between density, pressure, internal energy, stresses, and strains are required for this analysis. These relationships are equation of state (EOS), strength constitutive model, and failure criteria for each material component. The following subsections provide the details of the material models and parameters used for numerical analysis.

4.1. Material Model for Air. In this study, the strength models and failure criteria models are not required as it is air blast and these parameters are usually required in undermining blast experiment. The following equation of state (EOS), as given by equation (2), is used for the air as it was assumed that the surrounded air is an ideal gas.

$$
p=(\gamma-1) \rho e .
$$

Here, $p$ is the pressure, $\gamma$ is the constant of adiabatic process, which is estimated to be 1.4 for ideal gas, $\rho$ is the specific mass, and $e$ is the specific internal energy of the air. The parameters values of ideal gas EOS are listed in Table 2, which are adopted from ANSYS-Autodyn material library.

4.2. Material Model for Wabox Explosive. The Jones-WilkinsLee (JWL) [20] equation of state is formulated for the modelling of Wabox explosive material. JWL equation of states correlates chemical properties such as energy, volume, and pressure of high energy explosive products. The JWL equation of state in mathematical form is given by

$$
p=A\left(1-\frac{\omega}{R_{1} V}\right) e^{R_{1} V}+B\left(1-\frac{\omega}{R_{2} V}\right) e^{R_{2} V}+\frac{\omega e}{V},
$$

where $A, B, R_{1}, R_{2}, \omega$ are derived empirical constants which have different values for different explosive materials, $V$ define the expansion of the detonating materials, and $e$ is the specific energy at detonation stage.

The input parameters values of the JWL equation of state used for Wabox explosive (TNT equivalent $=1.1$ ) are taken from Abbas et al. [21] and remaining properties are available in ANSYS-Autodyn which are summarised in Table 3. In this study, the Eulerian solver (multimaterial) was employed for modelling both air and explosive material.

4.3. Material Model for Reinforced Concrete. In this study, the Riedel-Hiermaier-Thoma (RHT) material model of Riedel et al. [22], implemented in ANSYS-Autodyn, has been used for reinforced concrete. This model is extensively used for concrete and brittle materials to predict their response under blast load. In the RHT model for concrete, the two basic parameters, compressive strength $\left(f_{c}\right)$ and tensile strength $\left(f_{\mathrm{t}}\right)$ obtained from uniaxially loaded cylinder test, are required. The remaining parameters of concrete are derived from these parameters. The concrete strength in 


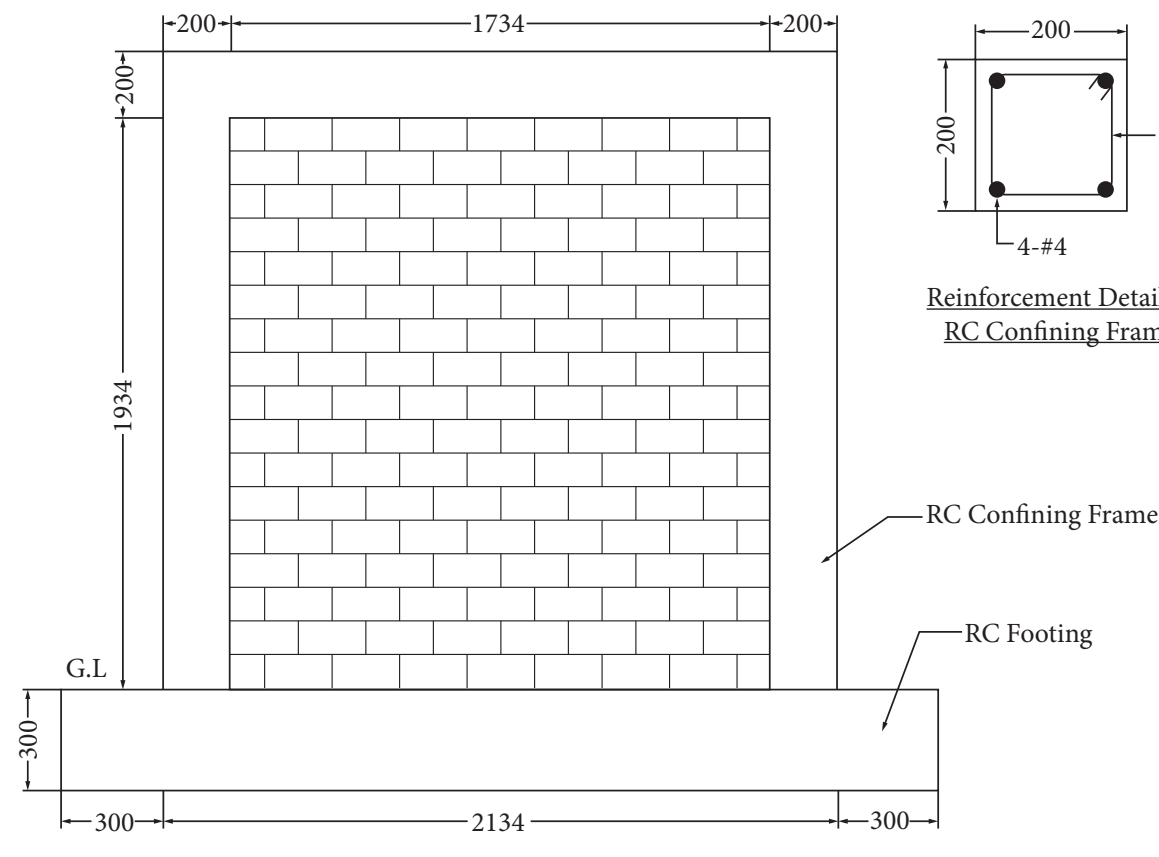

$\underline{\text { All Dimensions are in Millimeters }}$

FIgURE 2: Geometric description of test model wall with dimensions and reinforcement detail of RC confining frame.

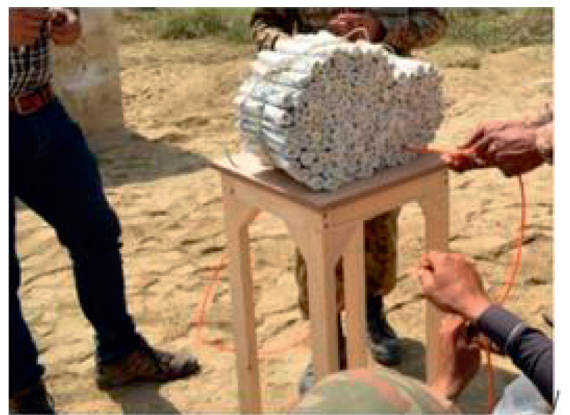

(a)

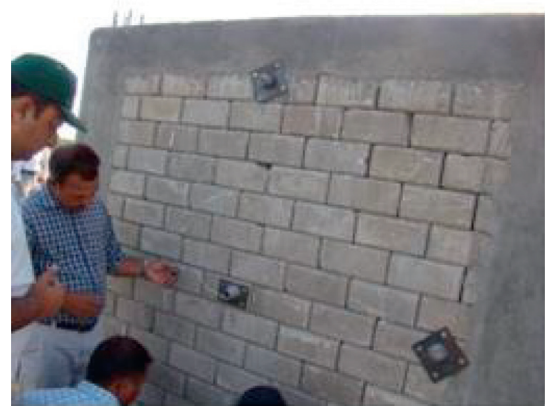

(b)

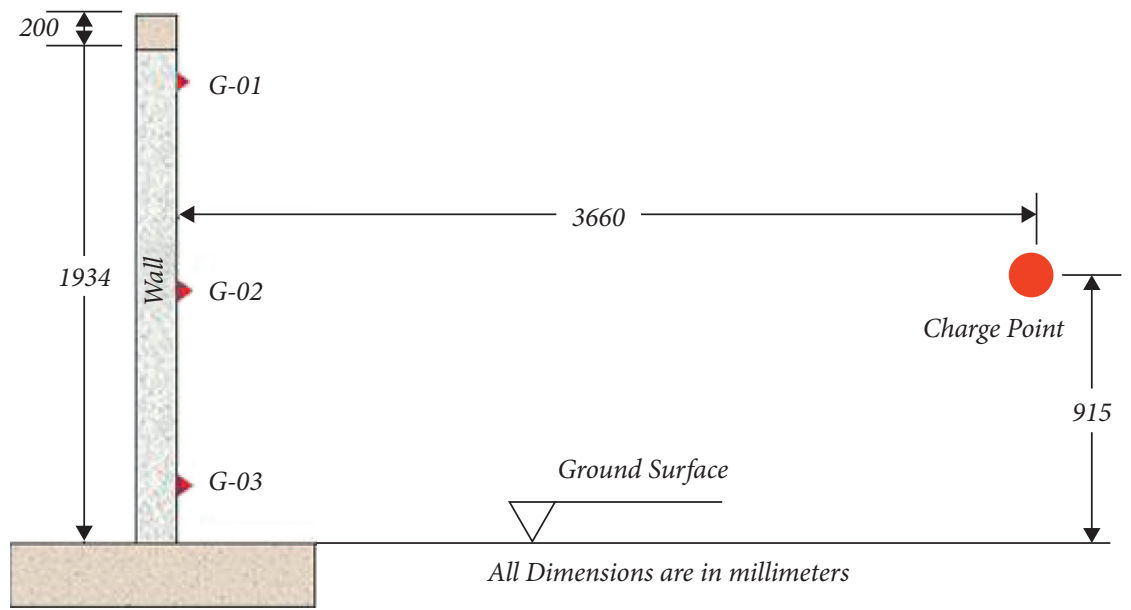

(c)

Figure 3: Detail of explosive and pressure sensors for field tests. (a) Wabox explosive. (b) Installation of pressure sensors [18]. (c) Geometrical description of test setup. 
TABLE 1: Detail of parameters for blast load tests.

\begin{tabular}{lcccc}
\hline & Test 1 & Test 2 & Test 3 & Test 4 \\
\hline Wabox charge mass $(\mathrm{kg})$ & 4 & 8 & 12 & 16 \\
Standoff distance $(\mathrm{m})$ & 3.66 & 3.66 & 3.66 & 3.66 \\
Charge height $(\mathrm{m})$ & 0.91 & 0.91 & 0.91 & 0.91 \\
Scaled distance $\left(\mathrm{m} / \mathrm{kg}^{1 / 3}\right)$ & 2.23 & 1.77 & 1.55 & 1.41 \\
\hline
\end{tabular}

TABLE 2: Material model parameter values for air (equation of state: ideal gas).

\begin{tabular}{lc}
\hline EOS parameter & Value \\
\hline Reference density, $\rho\left(\mathrm{kg} / \mathrm{m}^{3}\right)$ & 1.225 \\
Heat capacity ratio, $\gamma$ & 1.4 \\
Adiabatic constant & 0.0 \\
Pressure shift & 0.0 \\
Ref. temp. $(\mathrm{K})$ & 288.2 \\
Spec. heat $(\mathrm{J} / \mathrm{kg} \mathrm{K})$ & 717.6 \\
Initial internal energy $(\mathrm{kJ} / \mathrm{kg})$ & $2.0 E+5$ \\
\hline
\end{tabular}

TABle 3: Material model parameter values for Wabox explosive (equation of state: JWL).

\begin{tabular}{lc}
\hline EOS parameter & Value \\
\hline Reference density, $\rho\left(\mathrm{kg} / \mathrm{m}^{3}\right)$ & $1.42 E+3$ \\
State variable, $A(\mathrm{MPa})$ & $609.7 E+3$ \\
State variable, $B(\mathrm{MPa})$ & $12.9 E+3$ \\
State variable, $R_{1}$ & 4.5 \\
State variable, $R_{2}$ & 1.4 \\
State variable, $w$ & 0.2 \\
Velocity of wave, $v(\mathrm{~m} / \mathrm{s})$ & $8.2 E+3$ \\
Specific energy, $e\left(\mathrm{MJ} / \mathrm{m}^{3}\right)$ & $9.0 E+3$ \\
Initial pressure, $p(\mathrm{MPa})$ & $28.0 E+3$ \\
\hline
\end{tabular}

RHT is controlled by three strength failure surfaces: initial surface also called elastic limit surface, failure surface, and postfailure surface (residual surface) as shown in Figure 4. In this model, high tensile strength of concrete has been adopted to incorporate the tensile strength of mild steel reinforcement bars based on the study of Luccioni et al. [8]. Therefore, modified properties of reinforced concrete, as listed in Table 4, have been used.

Based on the hydrostatic behaviour of porous concrete the RHT model utilizes the $p-\alpha$ equation of state (EOS) model of Herrmann [23]. EOS is a function that mathematically correlates hydrostatic pressure, specific volume, and internal energy. This equation of state model is adopted in this research to capture the key global response of the wall. The input parameter values, that define the $p$ - $\alpha$ equation of state, are adopted from ANSYS-Autodyn materials library which are listed in Table 4.

4.4. Material Model for Dry-Stack Masonry. In numerical modelling, masonry walls can be modelled using either micro- or macromodel. Micromodel is distinctive simulation of masonry while macromodel is a homogenized simulation. In this study, homogenized macromodel is used

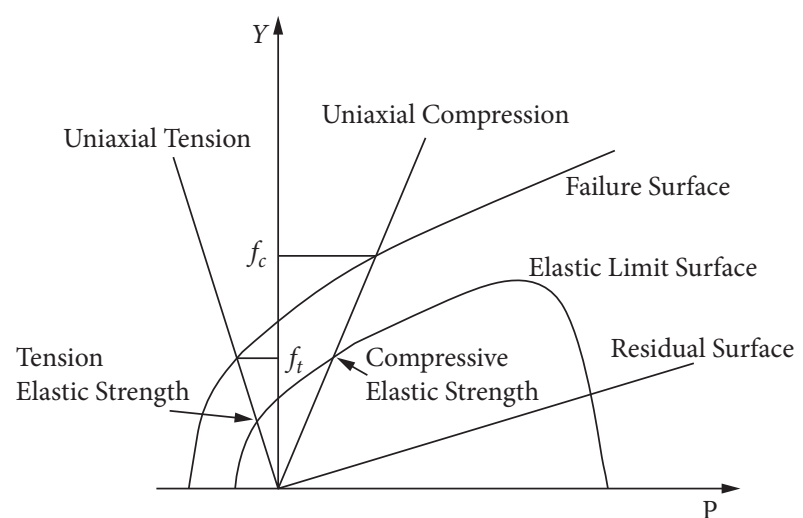

FIgURE 4: Failure surfaces of RHT concrete model.

for masonry wall to characterize Hydraform blocks and joints properties [24-28]. The use of macromodelling for masonry substantially optimises the computational time and cost for simulation. Therefore, it can be efficiently employed when microscopic response is not important like in case of extreme loads [29]. In this study, dry-stack masonry was modelled as homogenous low-strength concrete as the wall is constructed from concrete Hydraform blocks. The mechanical properties of Hydraform blocks and dry-stack masonry are taken from Hafeez [19] and the remaining input parameters are adopted from ANSYS-Autodyn material library which are listed in Table 5.

\section{Finite Element Model Parts}

The finite element model was developed in the software which is composed of CDSM wall and air volume by the wall. Due to symmetry, only half of the physical air domain and wall was modelled to reduce the computation costs. The model for CDSM wall is developed with three different Lagrangian parts, i.e., RC footing, confining elements, and dry-stack masonry wall. The 8-noded hexahedral solid elements of size $50 \mathrm{~mm}$ have been used in all three Lagrangian parts. Figure 5 illustrates the finite element meshing grid of the model, pressure gauge's location, and detonation. In this model, a fixed boundary condition was adopted by using unbreakable connection between the confining frame and footing, whereas stress-criteria based breakable connections were assumed between the masonry and confining frame. The details of input parameters for breakable connection are listed in Table 6.

The surrounded air part of the model was modelled as Eulerian, ideal gas. A three-dimensional (3D) domain of cuboid-shaped was created for surrounded air. The sizes of surrounded air domain are $4.22 \times 2.40 \times 2.20 \mathrm{~m}$. The element dimension for air volume is used as $25 \mathrm{~mm}$ which is an optimised size based on mesh convergence studies.

\section{Erosion Criteria}

As per the study carried out by researcher [32, 33], the elements of the reinforced concrete confining frame were 
TABLE 4: Material properties for confining reinforced concrete (state equation: $p-\alpha$, strength model: RHT).

\begin{tabular}{lccc}
\hline EOS parameter & Value & Strength parameter & Value \\
\hline Initial density, $\rho_{\mathrm{o}}\left(\mathrm{kg} / \mathrm{m}^{3}\right)$ & $2.3 E+3$ & Compressive strength, $f_{\mathrm{c}}(\mathrm{MPa})$ & 21.0 \\
Reference density, $\rho_{\mathrm{o}}\left(\mathrm{kg} / \mathrm{m}^{3}\right)$ & $2.75 E+3$ & Tensile strength, $f_{\mathrm{t}}(\mathrm{MPa})$ & 10.0 \\
Porous sound speed $(\mathrm{m} / \mathrm{s})$ & $2.75 E+3$ & Failure surface constant, $A_{\mathrm{c}}$ & 1.60 \\
Initial compaction, $O_{\mathrm{c}}(\mathrm{MPa})$ & 23.3 & Failure surface exponent, $N_{\mathrm{c}}$ & 0.61 \\
Solid compaction, $O_{\mathrm{s}}(\mathrm{MPa})$ & $6.0 E+3$ & Parameter, $Q_{\mathrm{o}}$ & 0.68 \\
Compaction exponent, $n_{\mathrm{c}}$ & 3.0 & Parameter, $Q_{1}$ & 0.011 \\
Bulk modulus, $K(\mathrm{MPa})$ & $35.2 E+3$ & Fractured constant, $B_{\mathrm{c}}$ & 1.60 \\
State variable, $A_{2}(\mathrm{MPa})$ & $39.5 E+3$ & Fractured exponent, $M_{\mathrm{c}}$ & 0.61 \\
State variable, $A_{3}(\mathrm{MPa})$ & $9.0 E+3$ & Damage parameter, $D_{1}$ \\
State variable, $B_{\mathrm{o}}$ & 1.22 & Damage parameter, $D_{2}$ \\
State variable, $B_{1}$ & 1.22 & Failure strain (minimum), $\epsilon_{\mathrm{f}}$ \\
State variable, $T_{1}(\mathrm{MPa})$ & $35.2 E+3$ & Shear modulus fraction & 0.04 \\
State variable, $T_{2}(\mathrm{MPa})$ & 0.0 & Principal tensile stress $(\mathrm{MPa})$ & 0.01 \\
Reference temperature $(K)$ & 300.0 & Fracture energy, $G_{\mathrm{f}}\left(\mathrm{J} / \mathrm{m}^{2}\right)$ \\
Specific heat $(\mathrm{J} / \mathrm{kg} \mathrm{K})$ & 654.0 & Erosion parameter & 0.13 \\
& & Erosion limit & 10.0 \\
\hline
\end{tabular}

TABLe 5: Material properties used for dry-stack masonry (state equation: $p-\alpha$, strength model: RHT).

\begin{tabular}{lc}
\hline Strength parameter & Value \\
\hline Compressive strength, $f_{\mathrm{c}}(\mathrm{kPa})$ & $5.0 E+3$ \\
Tensile strength, $f_{\mathrm{t}}(\mathrm{kPa})$ & 400 \\
Principal tensile stress $(\mathrm{kPa})$ & 400 \\
Elastic modulus, $E(\mathrm{MPa})$ & $4.2 E+3$ \\
Softening criteria & $\mathrm{Nil}$ \\
Erosion parameter & Strain \\
Erosion limit & 0.02 \\
\hline
\end{tabular}

Remaining properties are the same as used for reinforced concrete.

permitted to erode from the system when the level of geometric strain (instantaneous) reaches 0.5 . But dry-stack masonry geometric strain (instantaneous) of 0.02 was assumed as a criterion for the erosion of wall elements. These erosion models are adopted in ANSYS-Autodyn to avoid extreme and impractical deformation of mesh or grid system and also to model the fragmentation of wall parts.

\section{Blast Analysis in ANSYS-Autodyn}

The blast load analysis of the CDSM wall in ANSYSAutodyn was performed in two phases. The first phase, which is a one-dimension (1D) analysis, simulates the earlystage time expansion of blast wave in $1 \mathrm{D}$ using radial symmetry. This expansion of pressure wave continues until it hits the reflecting boundary. In the second phase, the output of the $1 \mathrm{D}$ analysis is then transferred to the $3 \mathrm{D}$ domain which is created independently. In this study, the explosive material is installed at $0.92 \mathrm{~m}$ above the ground surface. Therefore, it is considered as air blast and ground shocks are ignored due to its negligible effects.

7.1. 1D ANSYS-Autodyn Analysis. In 1D analysis, the expansion of blast wave, generated after the explosive detonation of material in the surrounding air, was first modelled and simulated. The problem in this stage can be treated as one-dimensional (1D) due to spherical symmetry, and a wedge is defined for the problem domain. The wedge geometric dimensions are specified on the basis of mass of explosive material and standoff distance. The finite element model of the wedge for the blast test of $16 \mathrm{~kg}$ Wabox at $3.66 \mathrm{~m}$ standoff distance is shown in Figure 6. The inner radius of the wedge is kept equal to $1 \mathrm{~mm}$ to avoid the zero thickness of the element at the origin. However, when this correction is employed, it reduces the weight of the explosive material, but its effect is insignificant due to small percentage reduction. The wedge model is filled with explosive material and surrounding air. The dimension of the elements in wedge is taken as $2 \mathrm{~mm}$ for achieving the desired level of accuracy and less computational time [34].

The output of this $1 \mathrm{D}$ analysis was later remapped in $3 \mathrm{D}$ domain of the model which was developed separately. The $3 \mathrm{D}$ domain of the model represents the wall with occupied air volume. This remapping technique reduces drastically the computational time and cost of the analysis. Figure 6 shows the plot of pressure contours at the end of the 1D analysis for $16 \mathrm{~kg}$ Wabox at $3.66 \mathrm{~m}$ standoff distance. The $1 \mathrm{D}$ blast analysis was carried out for four different scaled distances covering different charge weight of blast tests.

7.2. 3D ANSYS-Autodyne Analysis. The $1 \mathrm{D}$ analyses results were remapped onto the $3 \mathrm{D}$ domain already modelled with wall and surrounded air, separately. During remapping process, the center position of explosive charge from wall, that is, its standoff distance and height from ground, is defined in the remap dialogue box of ANSYS-Autodyn. In 3D analysis, fully coupled simulation was assumed between Lagrangian parts and air. The pressure waves at the start of the $3 \mathrm{D}$ analysis for $12 \mathrm{~kg}$ Wabox test are shown in Figure 7. All the foundation element nodes were assigned zero translational velocities which simulates fixed boundary condition for the wall at ground level. In ANSYS-Autodyn, Eulerian boundaries adopt reflecting boundary condition by default unless the specified boundary condition is assigned. Therefore, flow-out boundary condition was first defined in ANSYS-Autodyn and then assigned to the outer surfaces of 


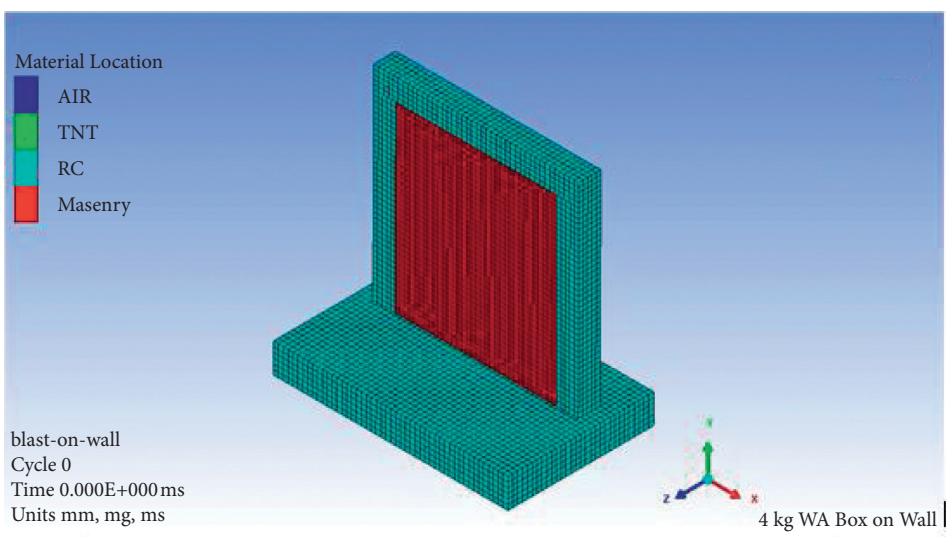

(a)

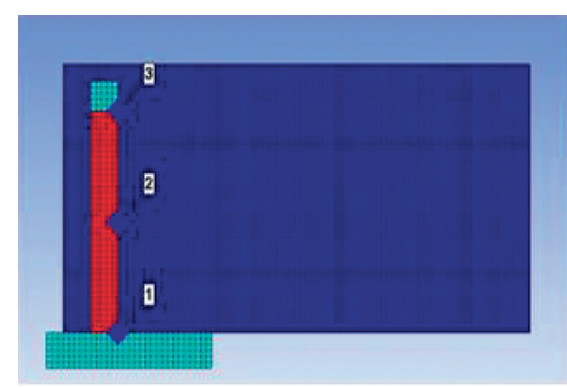

(b)

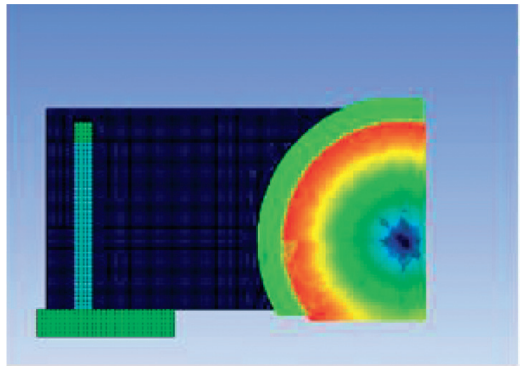

(c)

Figure 5: (a) Finite element (FE) model of the test specimen with meshing; (b) wall section enclosed in air domain with added pressure gauges; (c) explosive material detonation.

TABLE 6: Breakable connection failure parameter detail [30, 31].

\begin{tabular}{lcc}
\hline Connection & $\begin{array}{l}\text { Compressive } \\
\text { strength }\left(S_{n}\right)\end{array}$ & Shear strength $\left(S_{s}\right)$ \\
\hline $\begin{array}{l}\text { Wall and confining } \\
\text { element interface }\end{array}$ & $S_{n}=S_{s} / 3.1$ & $S_{s}=0.62 \sqrt{\min \left(f_{c}^{\prime}, f_{m}^{\prime}\right)}(\mathrm{MPa})$ whereas $f_{c}^{\prime}=$ confining concrete compressive strength \\
$f_{m}^{\prime}=$ dry-stack masonry compressive strength
\end{tabular}

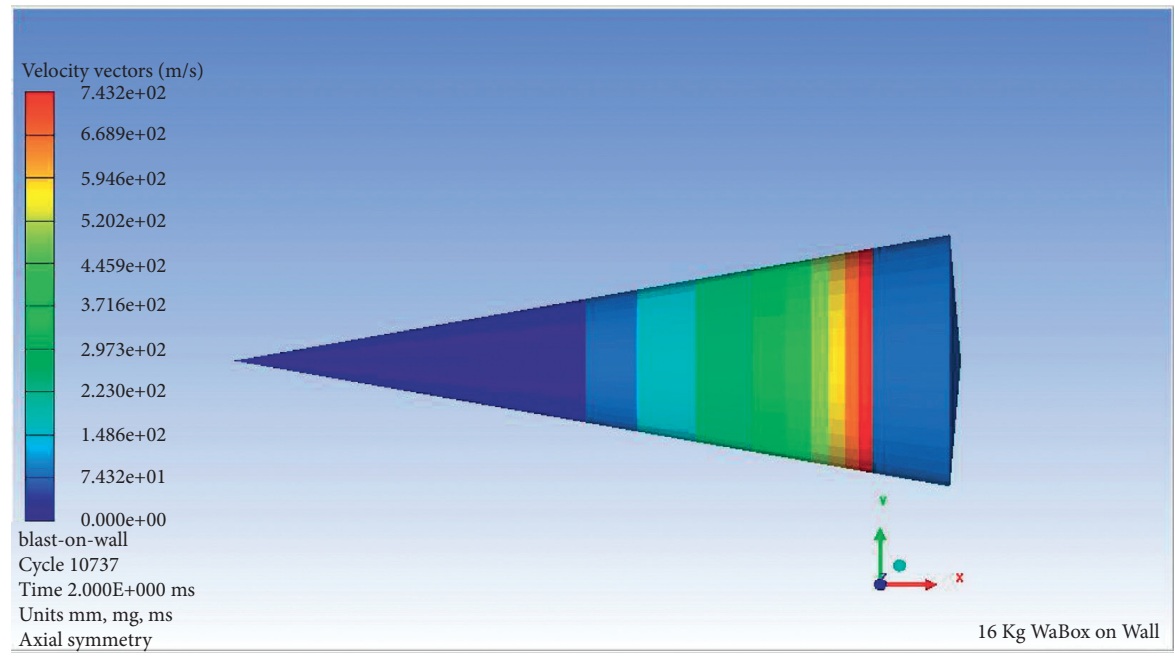

FIgure 6: Pressure contours in 1D wedge filled with Wabox explosive and air.

all air domain. The flow-out boundary condition allows the exit of pressure waves from 3D air domain outer surfaces without reflection of pressure waves back to the domain [35].
Moreover, the terminal time for the analysis was kept as $50.0 \mathrm{~ms}$ for the blast traveling time between detonation point and wall. For the complete analysis and response 


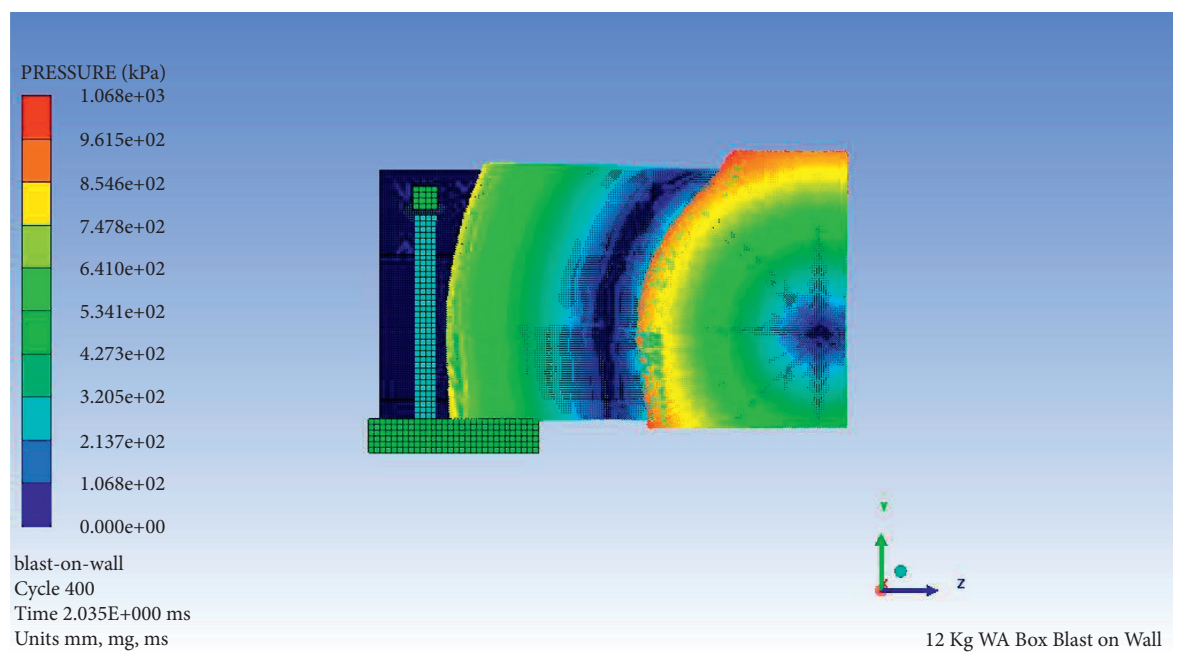

Figure 7: Pressure contours in 3D air domain after remapping from 1D output.

investigation of the wall specimen, this time is considered enough and appropriate.

\section{Results and Discussion}

A total of four charge weights detonations were simulated, of $4 \mathrm{~kg}, 8 \mathrm{~kg}, 12 \mathrm{~kg}$, and $16 \mathrm{~kg}$ of Wabox explosive material. Furthermore, the gauge installed at mid locations was considered for pressure-time history as per availability of the experimental data. The analysis of explosive detonation and CDSM response was carried out using software ANSYSAutodyn. The comparison of the results obtained from ANSYS-Autodyn was made with experimental data from Azmatullah [18] for pressure-time history and damage pattern which will be discussed in the coming sections.

8.1. Pressure-Time History. The pressure-time history comparisons between the experimental data and numerical simulation resulting from $4 \mathrm{~kg}, 8 \mathrm{~kg}, 12 \mathrm{~kg}$, and $16 \mathrm{~kg}$ Wabox explosive detonation are shown in Figure 8. Minor discrepancies have been observed in Figure 8 between the numerical simulation and experimental graphs. Experimental graphs of pressure-time history display some roughness in curves while smooth pressure profile has been obtained from the numerical simulation. Moreover, the pressure peaks and arrival time do not match by small margin. These minor differences are mainly due to the reflection effects of blast waves from ground, which can be detected by pressure sensors installed on the wall. These miner reflections were not considered in the ANSYSAutodyn model. However, there is still a general agreement between the pressure profiles of the numerical simulation and experimental tests. This validates that the numerical simulation in ANSYS-Autodyn is a reliable alternative for blast load tests on structures. From these graphs a comparison of incident overpressure and arrival time is illustrated in the coming subsections. The results were also calibrated with empirical model developed by KingeryBulmash [36] for incident overpressure and arrival time. The
Kingery-Bulmash equations have also been automated in the computer program CONWEP used for analysis of blast load.

8.1.1. Comparison of Peak Incident Overpressure. The summary of incident peak overpressure for different scaled distances obtained from ANSYS-Autodyn, experimental tests by Ullah [18], and Kingery-Bulmash model is given in Table 7 and is also plotted in Figure 9.

It is observed from Figure 9 that pressure variation trend for the three different model is nearly the same. The incident pressure values are also in close range except for the near field blast $\left(z=1.41 \mathrm{~m} / \mathrm{kg}^{1 / 3}\right)$.

8.1.2. Comparison of Arrival Time. Summary of results in terms of arrival time obtained from ANSYS-Autodyn, experimental tests, and Kingery-Bulmash empirical model is listed in Table 8.

The results comparison chart, as illustrated in Figure 10, displays the variation in arrival time values. However, the arrival time obtained from all three sources still shows a good correlation with slight variation which can be ignored for such type of large deformation or strain phenomenon.

8.2. Damage Pattern of Wall. The validation of the ANSYSAutodyn $3 \mathrm{D}$ results with the experimental tests conducted by Ullah [18] was carried out through damage or failure pattern. The failure pattern is based on the damage level contours obtained from numerical analysis at the end of each simulation which shows damage zones of the specimen. The numerical values for damage level contour ranges from 0.0 to 1.0 which represents no damage and full damage, respectively. The failure pattern obtained from the numerical simulation shows a good correlation with the experimental results as illustrated in the coming sections.

8.2.1. Damage Pattern of Blast Test \#1. In the first blast test, the CDSM wall was subjected to a blast of $4 \mathrm{~kg}$ explosive of Wabox at an altitude of $0.92 \mathrm{~m}$ and standoff distance of 


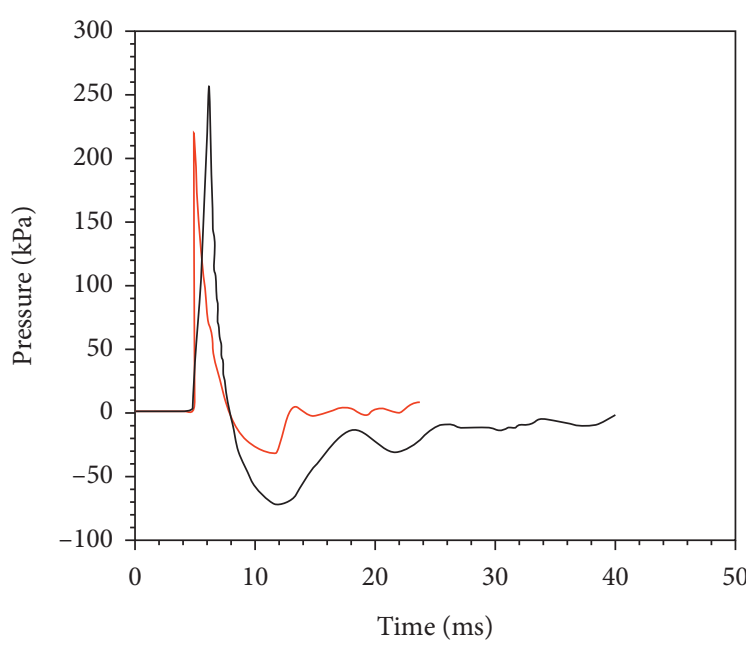

— Autodyn Numerical Simulation

— Experimental Work

(a)

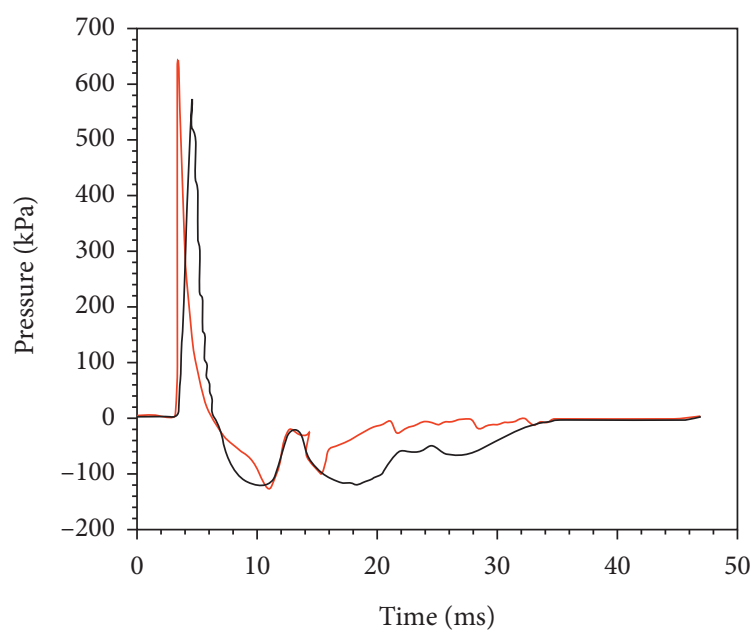

— Autodyn Numerical Simulation

— Experimental Work

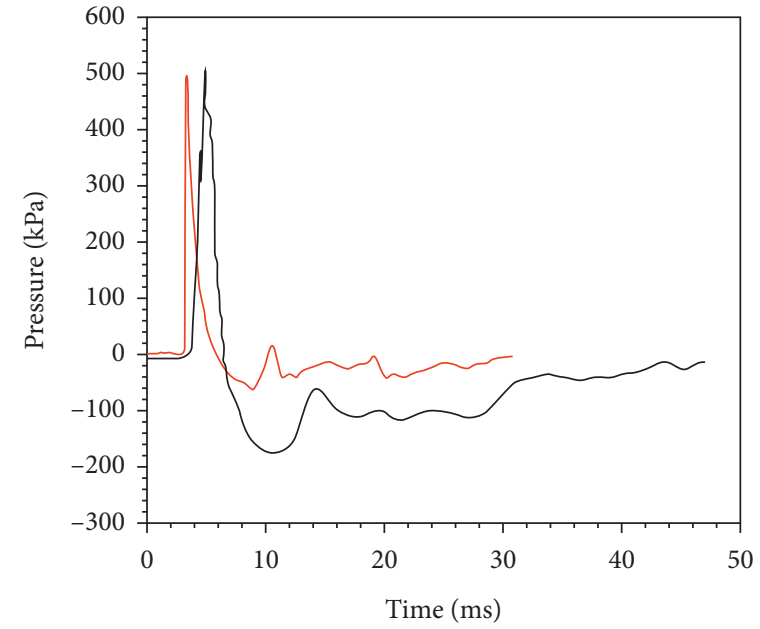

— Autodyn Numerical Simulation

_ Experimental Work

(b)

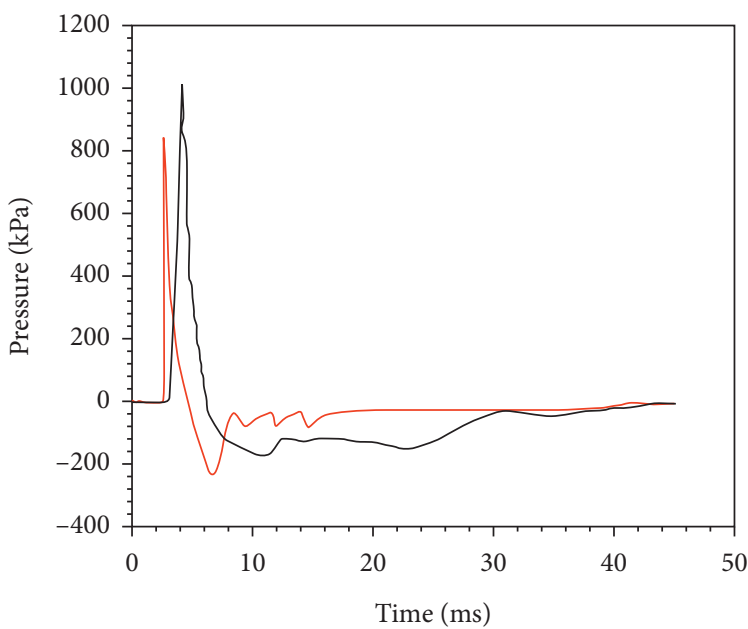

— Autodyn Numerical Simulation

— Experimental Work

c

d

(c)

(d)

Figure 8: Pressure-time history comparison for (a) 4 kg Wabox Blast; (b) 8 kg Wabox Blast; (c) 12 kg Wabox Blast; (d) 16 kg Wabox Blast.

TABLE 7: Summary of results of peak incident overpressure for wall specimen.

\begin{tabular}{lcccc}
\hline $\begin{array}{l}\text { Test } \\
\text { case }\end{array}$ & $\begin{array}{c}\text { Scaled distance, } \\
z=R / \sqrt[3]{W_{e}}\left(\mathrm{~m} / \mathrm{kg}^{1 / 3}\right)\end{array}$ & $\begin{array}{c}\text { Numerical peak incident } \\
\text { overpressure }(\mathrm{kPa})\end{array}$ & $\begin{array}{c}\text { Experimental peak incident } \\
\text { overpressure }(\mathrm{kPa})\end{array}$ & $\begin{array}{c}\text { Kingery-Bulmash peak incident } \\
\text { overpressure }(\mathrm{kPa})\end{array}$ \\
\hline 1 & 2.23 & 240 & 260 & 221 \\
2 & 1.77 & 490 & 498 & 375 \\
3 & 1.55 & 630 & 590 & 512 \\
4 & 1.41 & 895 & 1015 & 638 \\
\hline
\end{tabular}




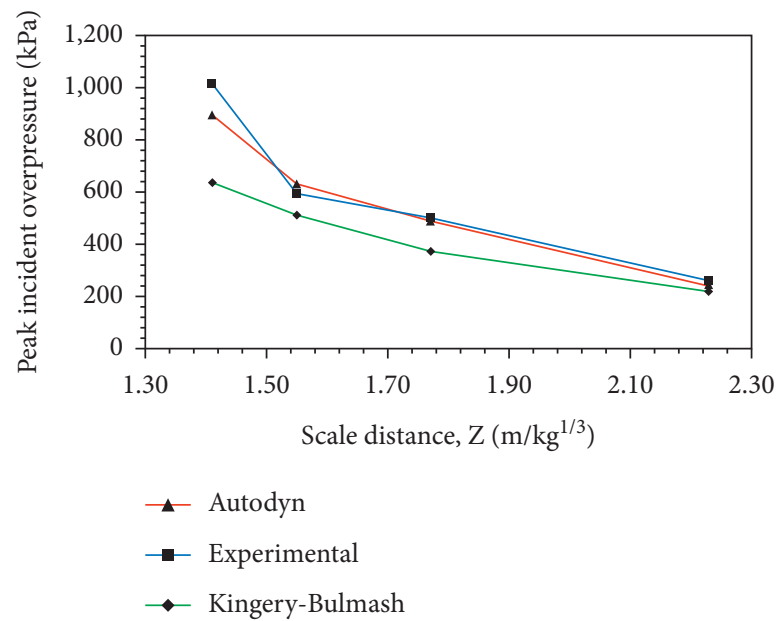

FIgURE 9: Peak incident overpressure comparison for different blast tests.

TABLE 8: Results summary of blast arrival time.

\begin{tabular}{lcccr}
\hline $\begin{array}{l}\text { Test } \\
\text { case }\end{array}$ & $\begin{array}{c}\text { Scaled distance, } \\
z=R / \sqrt[3]{W_{e}}\left(\mathrm{~m} / \mathrm{kg}^{1 / 3}\right)\end{array}$ & $\begin{array}{c}\text { Numerical peak incident } \\
\text { overpressure }(\mathrm{ms})\end{array}$ & $\begin{array}{c}\text { Experimental peak incident } \\
\text { overpressure }(\mathrm{ms})\end{array}$ & $\begin{array}{c}\text { Kingery-Bulmash peak incident } \\
\text { overpressure }(\mathrm{ms})\end{array}$ \\
\hline 1 & 2.23 & 3.97 & 4.00 & 3.41 \\
2 & 1.77 & 3.25 & 3.50 & 2.79 \\
3 & 1.55 & 2.85 & 2.55 & 2.48 \\
4 & 1.41 & 2.50 & 2.45 & 2.28 \\
\hline
\end{tabular}

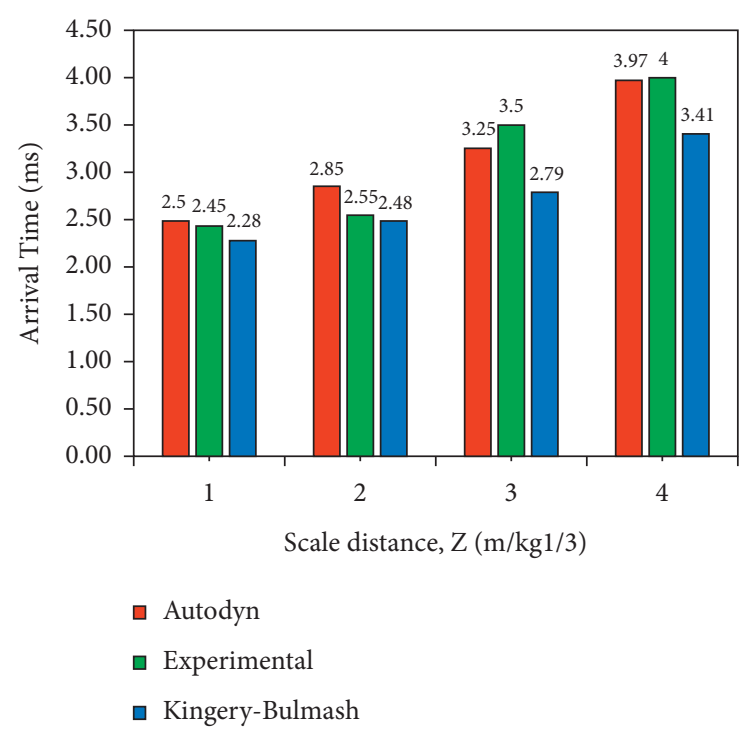

Figure 10: Arrival time comparison for different blast tests.

$3.66 \mathrm{~m}$. This blasting test of scaled distance, $2.23 \mathrm{~m} / \mathrm{kg}^{1 / 3}$, was of very low intensity; therefore, no damage has been observed to the wall as shown in Figure 11. After that, higher level intensity blast has been applied to the same wall specimen in the second blast which was named as blast test (\#2).

8.2.2. Damage Pattern after Blast Test \#2. It was found that for wall after $8 \mathrm{~kg}$ Wabox Blast (scaled distance of $1.77 \mathrm{~m} /$ $\mathrm{kg}^{1 / 3}$ ) minor cracked are observed at the interface of the masonry and confining frame as shown in Figure 12, which confirms the experimental result. The damage was minor; therefore, the same wall was used for the third blast test.

8.2.3. Damage Pattern after Blast Test \#3. Further damage was observed and the cracks between confining element and masonry interface were increased after $12 \mathrm{~kg}$ (scaled distance of $1.55 \mathrm{~m} / \mathrm{kg}^{1 / 3}$ ) blast. However, for the wall specimen with increased intensity level of blast load, the wall was still intact, and no global failure has been observed. This result also shows a good comparison with the experimental results as shown in Figure 13.

8.2.4. Damage Pattern after Blast Test \#4. In the final $16 \mathrm{~kg}$ Wabox explosion (scaled distance of $1.41 \mathrm{~m} / \mathrm{kg}^{1 / 3}$ ), the CDSM wall was completely damaged due to joint failure of the confining elements. The experienced damage level was high due to the debonding of the confining elements and blocks of the wall. This result also shows good conformance with the experimental test as shown in Figure 14. Although the left joint of the confining frame is intact, the right side joint failed by stress concentration which may be due to poor construction.

Based on the above simulations, a decent correlation has been attained between the obtained damage patterns of numerical analysis and field experiments of all four blast tests on the CDSM wall. This shows the validity of the numerical modelling analyses in capturing the real behaviour of CDSM wall exposed to blast loads. 


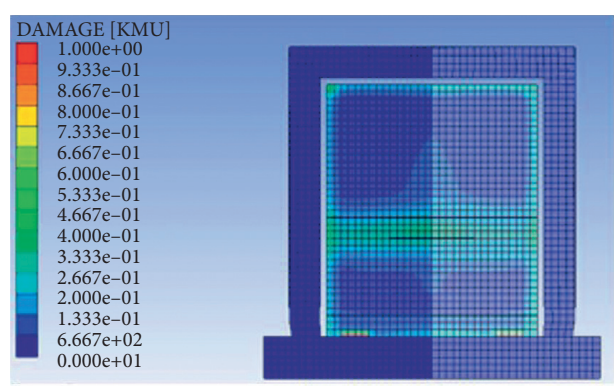

(a)

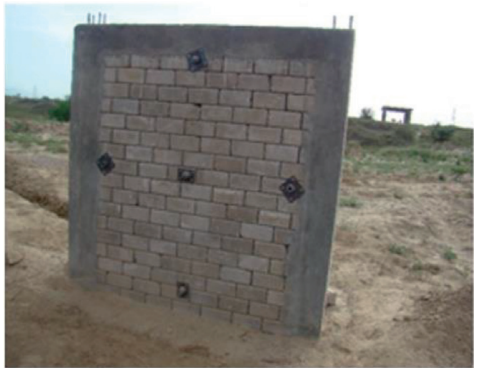

(b)

FIgURE 11: Damage pattern comparison for $4 \mathrm{~kg}$ Wabox Blast: (a) numerical results; (b) experimental results.

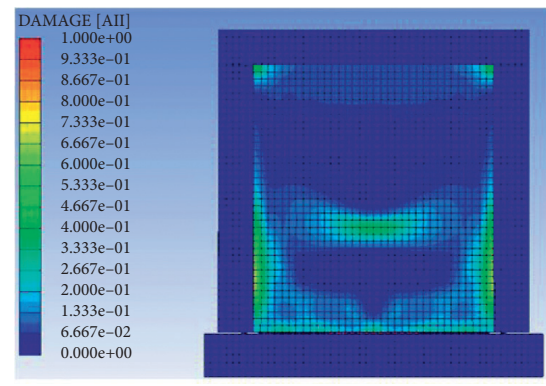

(a)

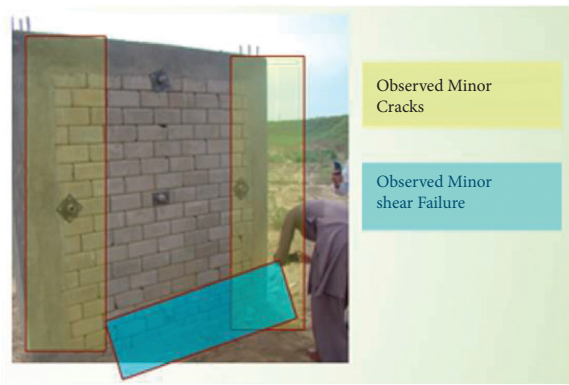

(b)

FIgURE 12: Damage pattern comparison for $8 \mathrm{~kg}$ Wabox Blast: (a) numerical results; (b) experimental results.

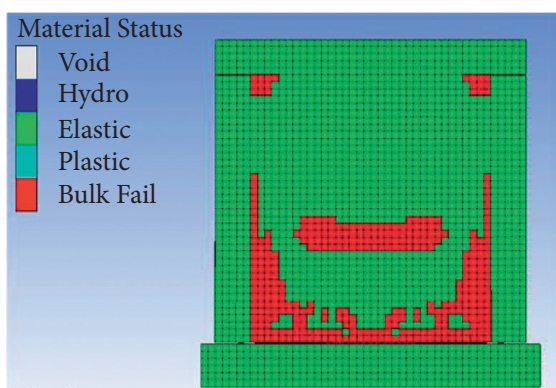

(a)

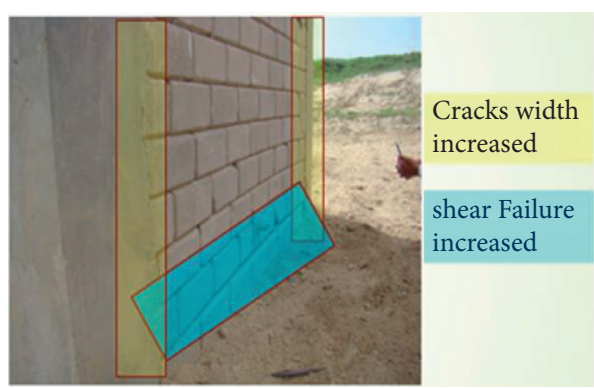

(b)

Figure 13: Damage pattern comparison for $12 \mathrm{~kg}$ Wabox Blast: (a) numerical results; (b) experimental results.

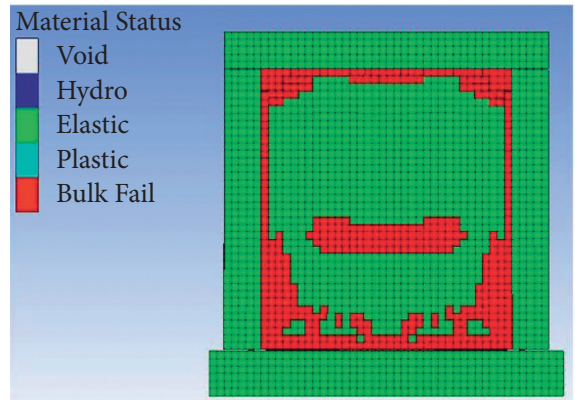

(a)

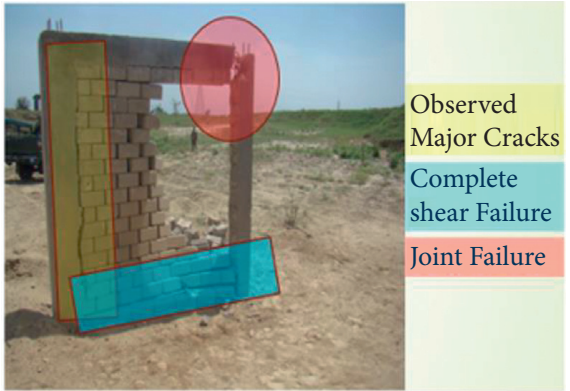

(b)

Figure 14: Damage pattern comparison for $16 \mathrm{~kg}$ Wabox Blast: (a) numerical results; (b) experimental results. 


\section{Conclusion}

Four different test cases of explosive charge detonation and blast wave propagation in open space on CDSM wall were investigated numerically using ANSYS-Autodyn software. From this numerical simulation study, the following were concluded.

(i) The complex wave structure of blasts was analysed and pressure-time history records on walls were described and compared with experimental records which shows good agreement.

(ii) The incident overpressure and arrival time values obtained from pressure-time history records were compared with experimental data and empirical models for calibration. The numerical model output values show good correlation with experimental and empirical models.

(iii) The numerical analysis is able to predict damage pattern with reasonable accuracy. Thus, the obtained damage patterns for each test were compared with experimental damage map which shows good correlation. Therefore, this numerical model can also be employed for parametric study on CDSM walls.

(iv) It is observed from the results of numerical analysis that the out-of-plane flexure capacity of CDSM walls against blast loads has been increased by providing proper confining elements. This also confirms the response of CDSM walls observed in the experimental tests conducted in the field.

\section{Data Availability}

The simulation data used to support the findings of this study are included within the article.

\section{Conflicts of Interest}

The authors declare that there are no conflicts of interest regarding the publication of this study.

\section{Acknowledgments}

The work was financially supported by the Higher Education Commission, Islamabad, Pakistan (Project code: TDF-(02038)), for executing scientific activities in the country. The authors are grateful to ECO Enterprises for providing the concrete blocks and financial support.

\section{References}

[1] A. Ismail and S. Amjad, "Determinants of terrorism in Pakistan: an empirical investigation," Economic Modelling, vol. 37, pp. 320-331, 2014.

[2] S. Yao, D. Zhang, X. Chen, F. Lu, and W. Wang, "Experimental and numerical study on the dynamic response of RC slabs under blast loading," Engineering Failure Analysis, vol. 66, pp. 120-129, 2016.

[3] Century Dynamics Inc, “Autodyn," 2011.
[4] K. Lin, Y. Totoev, H. Liu, and C. Wei, "Experimental characteristics of dry stack masonry under compression and shear loading," Materials, vol. 8, no. 12, pp. 8731-8744, 2015.

[5] I. G. Castro, P. T. Laursen, D. C. Jansen, and B. Qu, "Performance of interlocking compressed earth block infill in confined masonry construction," in Proceedings of the $\mathrm{Na}$ tional Conference on Earthquake Engineering Frontiers of Earthquake Engineering, Anchorage, AK, USA, July 2014.

[6] H. C. Uzoegbo, "Dry-stack and compressed stabilised earthblock construction," Nonconventional and Vernacular Construction Materials, Woodhead Publishing, Sawston, UK, pp. 205-249, 2016.

[7] K. Lin, Y. Z. Totoev, H. J. Liu, and A. W. Page, "Modeling of dry-stacked masonry panel confined by reinforced concrete frame," Archives of Civil and Mechanical Engineering, vol. 14, no. 3, pp. 497-509, 2014.

[8] B. M. Luccioni, R. D. Ambrosini, and R. F. Danesi, "Analysis of building collapse under blast loads," Engineering Structures, vol. 26, no. 1, pp. 63-71, 2004.

[9] B. Luccioni, D. Ambrosini, and R. Danesi, "Blast load assessment using hydrocodes," Engineering Structures, vol. 28, no. 12, pp. 1736-1744, 2006.

[10] M. D. Theobald and G. N. Nurick, "Experimental and numerical analysis of tube-core claddings under blast loads," International Journal of Impact Engineering, vol. 37, no. 3, pp. 333-348, 2010.

[11] G. Thiagarajan, A. V. Kadambi, S. Robert, and C. F. Johnson, "Experimental and finite element analysis of doubly reinforced concrete slabs subjected to blast loads," International Journal of Impact Engineering, vol. 75, pp. 162-173, 2015.

[12] C. Wu, H. Hao, and Y. Lu, "Dynamic response and damage analysis of masonry structures and masonry infilled RC frames to blast ground motion," Engineering Structures, vol. 27, no. 3, pp. 323-333, 2005.

[13] M. Ghaderi, V. A. Maleki, and K. Andalibi, "Retrofitting of unreinforced masonry walls under blast loading by FRP and spray on polyurea," Cumhuriyet Science Journal, vol. 36, pp. 462-477, 2015.

[14] B. Hopkinson, British Ordnance Board Minutes 13565, Vol. 11, The National Archives, , Kew, UK, 1915.

[15] S. H. Alsayed, H. M. Elsanadedy, Z. M. Al-Zaheri, Y. A. AlSalloum, and H. Abbas, "Blast response of GFRP-strengthened infill masonry walls," Construction and Building Materials, vol. 115, pp. 438-451, 2016.

[16] I. E. Edri and D. Z. Yankelevsky, "Analytical model for the dynamic response of blast-loaded arching masonry walls," Engineering Structures, vol. 176, pp. 49-63, 2018.

[17] G. Michaloudis and N. Gebbeken, "Modeling masonry walls under far-field and contact detonations," International Journal of Impact Engineering, vol. 123, pp. 84-97, 2019.

[18] A. Ullah, Capacity Assesement of Confined Block Masonry Buildings against Blast Loading, UET, Peshawar, Pakistan, 2019.

[19] J. Hafeez, Evaluation of Mechanical Properties of Dry-Stack Block Masonry, UET, Peshawar, Pakistan, 2017.

[20] E. L. Lee, H. C. Hornig, and J. W. Kury, Adiabatic Expansion of High Explosive Detonation Products, University of California Radiation Laboratory, Livermore, CA, USA, 1968.

[21] A. Abbas, M. Adil, N. Ahmad, and I. Ahmad, "Behavior of reinforced concrete sandwiched panels (RCSPs) under blast load," Engineering Structures, vol. 181, pp. 476-490, 2019.

[22] W. Riedel, K. Thoma, and S. Hiermaier, "Penetration of reinforced concrete by BETA-B-500 numerical analysis using a new macroscopic concrete model for hydrocodes," in 
Proceedings of the 9th International Symposium on Interaction of the Effect of Munitions with Structures, pp. 315-322, Berlin, Germany, 1999.

[23] W. Herrmann, "Constitutive equation for the dynamic compaction of ductile porous materials," Journal of Applied Physics, vol. 40, no. 6, pp. 2490-2499, 1969.

[24] M. Wang, H. Hao, Y. Ding, and Z.-X. Li, "Prediction of fragment size and ejection distance of masonry wall under blast load using homogenized masonry material properties," International Journal of Impact Engineering, vol. 36, no. 6, pp. 808-820, 2009.

[25] X. Wei and H. Hao, "Numerical derivation of homogenized dynamic masonry material properties with strain rate effects," International Journal of Impact Engineering, vol. 36, no. 3, pp. 522-536, 2009.

[26] G. N. Pande, J. X. Liang, and J. Middleton, "Equivalent elastic moduli for brick masonry," Computers and Geotechnics, vol. 8, no. 3, pp. 243-265, 1989.

[27] P. D. Buhan and G. D. Felice, "A homogenization approach to the ultimate strength of brick masonry," Journal of the Mechanics and Physics of Solids, vol. 45, no. 7, pp. 1085-1104, 1997.

[28] F. Cluni and V. Gusella, "Homogenization of non-periodic masonry structures," International Journal of Solids and Structures, vol. 41, no. 7, pp. 1911-1923, 2004.

[29] G. Ma, H. Hao, and Y. Lu, "Homogenization of masonry using numerical simulations," Journal of Engineering Mechanics, vol. 127, pp. 421-431, 2001, https://doi.org/10.1061/.

[30] H. M. Elsanadedy, T. H. Almusallam, S. H. Alsayed, and Y. A. Al-Salloum, "Flexural strengthening of RC beams using textile reinforced mortar-experimental and numerical study," Composite Structures, vol. 97, pp. 40-55, 2013.

[31] J. Silfwerbrand, "Shear bond strength in repaired concrete structures," Materials and Structures, vol. 36, no. 260, pp. 419-424, 2003.

[32] H. M. Elsanadedy, T. H. Almusallam, H. Abbas, Y. A. AlSalloum, and S. H. Alsayed, "Effect of blast loading on CFRPretrofitted RC columns-a numerical study," Latin American Journal of Solids and Structures, vol. 8, no. 1, pp. 55-81, 2011.

[33] S. Lan and J. E. Crawford Kbm, "Design of reinforced concrete columns to resist the effects of suitcase bombs," in Proceedings of the 6th International Conference on Shock and Impact Loads on Structures, pp. 5-10, Australia, Perth, May 2005.

[34] R. A. Izadifard, "Blastwave parameters assessment at different altitude using numerical simulation," Turkish Journal of Engineering and Environmental Sciences, vol. 34, pp. 25-41, 2010.

[35] P. Sherkar, "Modeling the effects of detonations of high explosives to inform blast-resistant design," MS Thesis, State University of New York, Albany, NY, USA, 2010.

[36] C. N. K. Bulmash, "Air blast parameters from tnt spherical air burst and hemi-spherical surface burst," 1984. 